\title{
Covid-19 e as decisões governamentais no retorno presencial de uma rede privada de ensino do DF: um relato da equipe de psicologia escolar
}

Covid-19 and government decisions about the reopening of educational institutions in a particular school in Distrito Federal: a school psychology report

Covid-19 y decisiones governamental en el regreso presencial de una red de enseñanza en el DF: un informe del equipo de psicología escolar.

Rayanne Linhares Azevedo ORCID: https://orcid.org/0000-0001-9126-8480 Faculdade de Ciências da Saúde de Unaí, Brasil

E-mail: ray.linhares08@gmail.com

Beatriz Macedo Buchmann ORCID: https://orcid.org/0000-0003-3989-5801 Universidade de Brasília, Brasil E-mail: beatrizbuchmann.m@gmail.com Larissa Santos Lopes ORCID: https://orcid.org/0000-0001-5209-0800 Universidade de Brasília, Brasil E-mail: larissaunb2015@gmail.com

\begin{abstract}
Resumo
O artigo problematiza o retorno presencial de alunos da Educação Infantil e Ensino Fundamental I, de uma rede privada de ensino, em meio à pandemia da Covid-19. Analisou-se as ações amparadas pelo governo do Distrito Federal e a realidade das famílias de uma escola particular, buscando identificar os fatores que influenciaram o posicionamento dos responsáveis, no sentido de permitir o retorno de seus filhos à frequência presencial. A investigação metodológica foi por meio do relato de experiência, comparando-se as análises de questionários de satisfação enviados às famílias sobre as aulas on-line e pesquisas diretas, com o único intuito de conhecer o quantitativo das famílias com interesse no retorno presencial, e associando essas análises aos diferentes decretos publicados no DODF. Concomitantemente, há o respaldo bibliográfico em relação ao cenário escolar, apresentando, dessa forma, outras experiências vivenciadas durante a pandemia. Após análise, a discussão seguiu uma linha cronológica de pensamento, em um primeiro momento debatendo sobre a educação a distância, trazendo seus vários desafios, tanto da perspectiva bibliográfica como da perspectiva da Equipe de Psicologia da escola em questão. Em um segundo momento discutiu-se sobre a mudança de perspectiva dos responsáveis, em relação ao retorno presencial, com as decisões governamentais do momento, apesar da ascensão dos casos de Covid-19, na média móvel. Conclui-se que a pandemia da Covid-19 determinou, de algum modo, um momento de resiliência e criatividade dos professores, ao mesmo tempo que provocou desgaste emocional na comunidade escolar, refletindo-se também, sobre as desigualdades sociais entre escolas públicas e particulares.
\end{abstract}

Palavras-chave: Aulas on-line; Retorno presencial; Covid-19; Decisões governamentais; Perspectiva familiar; Emoções.

\begin{abstract}
The article discusses the return face students from Kindergarten and Elementary Education I, a private school system amid the pandemic Covid-19. Actions supported by the government of Distrito Federal were analyzed, as also the reality of families in a private school, seeking to identify factors that influenced the position of those responsible, in order to allow the return of their children during the reopening of educational educations. The methodological investigation was through experience report, comparing the analysis of satisfaction questionnaires sent to families about the online classes and direct surveys, with the sole intention of knowing the number of families interested in the face-to-face return, and associating these analyzes with different decrees, all published in DODF. Concomitantly, there is bibliographic support in relation to the school scenario, thus presenting other experiences lived during the pandemic. After analysis, the discussion followed a chronological line of thought, initially debating on distance education, bringing its various challenges, both from the bibliographic perspective and from the perspective of the Psychology Team of the school in question. In a second moment, it was discussed the change in the perspective of those responsible, in relation to the face-to-face return, with the government decisions of the moment, despite the rise of the Covid-19 cases. It is concluded that the Covid-19 pandemic determined, in some way, a moment of teachers' resilience and creativity, at the same time
\end{abstract}


that it caused emotional distress in the school community, also reflecting on the social inequalities between public and private schools.

Keywords: Online classes; Back to school; Covid-19; Government decisions; Family perspective; Emotions.

\section{Resumen}

El artículo problematiza el regreso presencial de alumnos de la educación infantil y enseñanza fundamental 1, de una red de enseñanza privada, en medio de una pandemia del covid-19. Analizado las acciones apoyadas por el gobierno del Distrito Federal y la realidad de las famílias de un colegio privado buscando identificar los factores que influyó en el posicionamiento de los responsables, a fin de permitir el regreso de sus hijos a tener asistencia presencial. La investigación metodológica fue a través del relato de experiencia, comprando los análisis con los diferentes decretos públicos en el DODF. Simultaneamente, pose soporte bibliográfico en relación al escenario escolar, apresentado, de esa forma, otras experiencias experimentadas durante la pandemia. Después del análisis la discusión siguió una línea cronológica de pensamiento, en primer momento debatiendo sobre educación a distancia, trayendo sus diversos desafíos, tanto desde la perspectiva bibliográfica como desde la perspectiva del equipo de psicología escolar en cuestión. En un segundo momento se discutió sobre el cambio de perspectiva de los responsables, en relación al retorno presencial, con las decisiones governamental desde el momento, a pesar del aumento de casos de Covid-19. Concluye que la pandemia de Covid-19 determinó, de alguna manera un momento de resiliência y creatividad de los maestros, en el mismo tiempo que provocó estrés emocional en la comunidad escolar, reflexionando también sobre las desigualdades sociales entre escuelas públicas y privadas.

Palabras clave: Clases virtuales; Regreso presencial; Covid-19; Decisiones governamental; Perspectiva familiar; Emociones.

\section{Introdução}

Em março de 2020, o Distrito Federal (DF) identificou os primeiros casos de infecção local pela nova Síndrome Respiratória Aguda Grave 2 (SARS-CoV-2), popularmente conhecida como coronavírus. Em resposta, o governo do DF agiu rapidamente por meio do decreto no 40.509, em edição extra do Diário Oficial do DF (DODF), de 11 de março de 2020, determinando o fechamento de todas as instituições de ensino durante cinco dias. A determinação seguia as orientações da Organização Mundial da Saúde (OMS), como medida não farmacológica para contenção da disseminação da doença.

A escola é um fator de proteção para o desenvolvimento da criança (Maia \& Williams, 2005) e, também para os adultos, possui importância social, cognitiva e emocional em sua função, abrangendo os principais contextos de desenvolvimento humano (Oliveira \& Marinho-Araújo, 2010). Assim, o fechamento das instituições de ensino impactou diretamente a rotina e o emocional de todos os envolvidos. Esse impacto pode reverberar de forma direta na saúde mental e no bem-estar psicológico dos que estão vivenciando tais mudanças (Schmidt et al., 2020). A princípio, as escolas de Brasília, em especial as particulares, implementaram as aulas on-line como estratégia para oferecer às crianças o prosseguimento do ano escolar. Com a evolução da situação da pandemia no DF, o período de fechamento das escolas se prolongou de forma gradativa, determinado por meio de diversos decretos publicados no Diário Oficial do Distrito Federal. Instalou-se então um cenário de incertezas quanto ao retorno às atividades presenciais, tanto por parte das instituições de ensino quanto por parte das famílias. Conforme a flexibilização das medidas de isolamento e distanciamento social para outros estabelecimentos foi sendo autorizada, as opiniões se dividiram entre os que defendiam o retorno às atividades presenciais nas escolas e os que consideravam prudente a continuidade das atividades on-line. Essa divisão de opiniões pôde ser verificada nas disputas judiciais entre o Sindicato dos Estabelecimentos Particulares de Ensino do Distrito Federal (Sinepe), o Sindicato dos Professores em Estabelecimentos Particulares de Ensino do Distrito Federal (Sinproep) e o Ministério Público do Trabalho [MPT], que marcaram o ano letivo de 2020 no território do DF.

No que diz respeito à reabertura das escolas, é imprescindível ressaltar o papel do Estatuto da Criança e do Adolescente (ECA) como norteador na tomada de decisão. Apesar do caráter extraordinário da pandemia e suas consequências na sociedade, o princípio da indivisibilidade dos direitos humanos, assegurados no artigo segundo do ECA, não poderia ser desconsiderado (Brasil, 1990). Tal princípio tem como objetivo a garantia de todos os direitos, isto é, o não favorecimento de um, em detrimento de outro (Fundo das Nações Unidas para a Infância (Unicef), 2005). No tema em questão, esse princípio se aplica, uma vez que 
é direito da criança o acesso à educação, mas também é direito da criança a proteção à saúde, não podendo haver hierarquização desses direitos.

O manejo da pandemia do novo coronavírus é complexo e multideterminado, demandando levar em consideração fatores sociais, econômicos, demográficos e de saúde mental da população, bem como sua evolução ao longo do tempo. Liang (citada em Linhares \& Emuno, 2020) alerta sobre os riscos do isolamento social prolongado em toda a população, em diferentes níveis. Nesse sentido, as crianças podem ser afetadas por questões como o adoecimento, a hospitalização ou a morte de entes queridos, com a possibilidade de prejudicar seu senso de segurança e normalidade. Há que avaliar também o fato de que o distanciamento social e a repentina interrupção da rotina desencadearam efeitos negativos na vida de crianças que apresentam demandas específicas, como aquelas que apresentam impedimentos psicossociais, neuropsicológicos ou corporais. Tais impactos podem ir desde a desorganização sensorial e psicológica até danos motores (Fundação Oswaldo Cruz, 2020).

Caminhando para o final do ano, já se tornou possível avaliar as evidências empíricas sobre o impacto do fechamento das escolas de forma inesperada. Oliveira, Gomes e Barcellos (2020) atestam que a forma abrupta pela qual precisou ser conduzido o fechamento das escolas afetou, a princípio, a aprendizagem das crianças, sendo que, em seguida, também outros aspectos começaram a ser impactados, como o social e o emocional. Em casa, as famílias vivenciaram mais de perto conflitos, tendo que conciliar as demandas do trabalho com a rotina escolar do filho e a da casa - o que, obviamente, fez com que os fatores estressores se intensificassem.

No cenário de tantas incertezas, sem saber quando e como se poderia retornar às aulas presenciais, cabem algumas problemáticas importantes, que este estudo aborda como relato de experiência. Como os pais perceberam as aulas on-line em um primeiro momento? Qual era a expectativa da escola e das famílias para o retorno presencial? Como os diferentes decretos relacionados à abertura de estabelecimentos afetaram o retorno às aulas presenciais? Quais medidas a escola precisou adotar pensando no retorno presencial? Nesse contexto, o presente artigo tem como objetivo investigar/analisar os possíveis fatores como variáveis independentes - que influenciaram o posicionamento das famílias em relação às atividades presenciais.

Diante de tal perspectiva, os objetivos específicos foram investigar cada variável de influência: a) a avaliação das aulas on-line, b) contexto em diferentes cenários (quantitativo de casos de infecção e óbitos por Covid-19 no DF, concomitantemente aos decretos com decisões relacionadas à pandemia) e c) relatos de abalo emocional das famílias, como fator de interesse ao retorno presencial, sob a perspectiva de uma escola particular da Educação Infantil e Ensino Fundamental I, localizada em Brasília-DF.

A publicação dos decretos governamentais foi fator decisivo e imprescindível para as ações durante a pandemia, influenciando não somente o contexto escolar, como também comércio, trabalho e lazer. Por isso, neste artigo, considerou-se analisar as ações amparadas pelo governo e, junto a isso, a realidade das famílias de uma escola particular, pois, assim como respalda Pedroza e Maia (2021), por mais que em meio a uma situação de emergência global, cada um possui sua percepção em relação a um fator, a forma de lidar com o ocorrido, perpassada por fatores econômicos, políticos e sociais, o que, por sua vez, afeta o processo de ensino e aprendizagem.

A investigação metodológica fez-se por meio do relato de experiência, comparando-se as análises de questionários enviados às famílias, sobre o interesse no retorno presencial, com os diferentes decretos publicados no DODF. O simultâneo respaldo bibliográfico em relação ao cenário escolar viabilizou o conhecimento de outras experiências vivenciadas durante a pandemia. Buscando melhor estruturar o artigo, ele foi dividido em: a) métodos b) análises referentes às aulas on-line c) percepções dos pais sobre o retorno presencial em função dos decretos do governo do DF. 


\section{Metodologia}

Para a elaboração deste relato foram utilizadas abordagens tanto qualitativas como quantitativas. Em relação aos dados quantitativos, foram enviados três questionários às famílias de uma escola particular, ao longo do ano letivo, todos em plataforma on-line, dirigidos aos adultos identificados nos registros da escola como responsáveis pela criança. Cada questionário foi elaborado em um período diferente do ano, de acordo com o cenário da pandemia, contexto do DF e perspectivas futuras então vigentes. Na escola em questão havia na época cerca de 1.400 alunos, distribuídos do maternal I (idade média 2,5 anos) ao quinto ano do Ensino Fundamental I (idade média 11 anos).

É importante destacar que esses questionários, na ocasião em que foram elaborados, não tinham como objetivo embasar uma pesquisa científica, mas sim suprir demandas urgentes e pontuais da escola, frente ao contexto vivenciado. Por isso, eles não atendem plenamente ao rigor do método de pesquisa científica, o que justifica a limitação do presente artigo. Para Lüdke e André (1986) este fluxo das etapas investigativas é uma característica de estudos qualitativos, os quais a partir de contato prolongado e direto no contexto de investigação, analisam os dados não a fim de confirmar uma hipótese predeterminada, mas sim compreender os dados coletados, valorizando a perspectiva dos participantes.

O primeiro questionário foi enviado para as famílias no mês de maio e teve como objetivo avaliar a adaptação das crianças e das famílias ao formato on-line de atividades naquele momento, buscando identificar quais eram as principais dificuldades enfrentadas e quais os aspectos positivos identificados pela família. Foram abordados temas como avaliação da plataforma utilizada para aulas on-line, relação professora/turma, relação criança/turma, tempo de duração das aulas, materiais físicos enviados, atividades propostas, percepção do emocional da criança na modalidade, entre outros.

O segundo questionário, remetido no começo de julho, visou a um levantamento da opinião das famílias em relação ao retorno às aulas presenciais, pois estimava-se que ele logo ocorresse, uma vez que o Sinepe/DF já estava buscando negociação com o governo e, ao mesmo tempo, algumas famílias começaram a procurar a escola, questionando a previsão do retorno. Na primeira parte do questionário solicitou-se que os responsáveis identificassem a criança, bem como o segmento cursado. Na segunda parte, foi perguntado se as famílias tinham interesse ou não na retomada das atividades presenciais. Finalmente, as famílias deveriam justificar a resposta anterior, marcando quantas opções julgassem necessárias, das dez indicadas no questionário e transcritas abaixo. Ao final, havia ainda um campo de resposta aberta "Outros", caso a família sentisse necessidade.

1. Sinto segurança em mandar o meu filho para a escola, se a escola cumprir todos os protocolos exigidos para o retorno.

2. Estou disposto a optar pelo retorno do meu filho à escola, após compreender os protocolos de segurança que a escola adotará.

3. Opto pelo retorno às aulas presenciais, pois não terei com quem deixar meu filho.

4. Opto pelo retorno às atividades presenciais, uma vez que o meu filho não se adaptou ao formato de aula on-line.

5. Acredito na retomada das atividades presenciais, em conjunto com as atividades on-line.

6. Opto pela continuidade das aulas on-line, pois ainda não estou segura de mandar meu filho para as atividades presenciais.

7. Não opto pelo retorno às aulas presenciais, mas acredito que seja prudente um retorno gradual.

8. Não opto pelo retorno às atividades presenciais, pois o meu filho é do grupo de risco.

9. Não opto pelo retorno às atividades presenciais, pois o meu filho convive com pessoas do grupo de risco.

10. Não opto pelo retorno às atividades presenciais, pois não estou segura com os riscos reais de transmissão do coronavírus. 
O terceiro questionário foi enviado às famílias em setembro, mês para o qual estava previsto o retorno das atividades das instituições de ensino da rede privada, conforme acordo firmado ao final de agosto entre os sindicatos e o Ministério Público do Trabalho. Diferentemente do que ocorrera na remessa do questionário anterior, ao enviar esse terceiro a escola já havia decidido a retomada das atividades presenciais para as famílias que assim desejassem. O questionário, portanto, foi enviado aos pais com o objetivo de obter controle sobre o número de alunos que voltariam para escola no período de sua reabertura. Nele informava-se que a não resposta da família seria interpretada como opção pela manutenção das aulas on-line.

Além disso, foram consultados os boletins epidemiológicos divulgados pela Secretaria de Estado da Saúde do Distrito Federal, para verificar o número de casos de infecção e de óbitos pela Covid-19 confirmados e registrados no DF, nas datas em que os decretos que regulamentavam o funcionamento das escolas foram publicados no DODF.

Assim, conforme Pereira et al. (2018) explicam, questionários com perguntas fechadas são frequentemente utilizados como ferramentas em pesquisas qualitativas. No presente relato de experiência, a análise qualitativa foi utilizada para relacionar os dados quantitativos às experiências subjetivas vivenciadas pelas autoras no decorrer do ano letivo, a partir do contato com as famílias em reuniões e atendimentos on-line, com as crianças e com os profissionais do corpo pedagógico.

\section{Resultados e Discussão}

\section{Educação a distância: o on-line como necessidade}

A seguir, no Quadro 1, apresentou-se o cenário da pandemia no Distrito Federal, de acordo com as datas de publicação dos decretos que determinaram a situação de funcionamento das escolas das redes de ensino pública e privada.

Quadro 1. Linha do tempo: a evolução da pandemia no DF e os impactos na educação básica.

\begin{tabular}{|c|c|c|c|c|}
\hline Data & $\begin{array}{l}\text { № total de casos } \\
\text { confirmados }\end{array}$ & $\begin{array}{l}\text { № total de óbitos } \\
\text { registrados }\end{array}$ & Decreto & Impacto no contexto escolar \\
\hline $11 / 03 / 2020$ & 2 & 0 & no 40.509 & $\begin{array}{l}\text { Suspensão por cinco dias das } \\
\text { atividades educacionais em todas as } \\
\text { escolas das redes de ensino pública } \\
\text { e privada }\end{array}$ \\
\hline $14 / 03 / 2020$ & 8 & 0 & no 40.520 & $\begin{array}{l}\text { Suspensão por } 15 \text { dias das } \\
\text { atividades educacionais em todas as } \\
\text { escolas, das redes de ensino pública } \\
\text { e privada }\end{array}$ \\
\hline $19 / 03 / 2020$ & 42 & 0 & n- 40.539 & $\begin{array}{l}\text { Suspensão até o dia } 05 \text { de abril das } \\
\text { atividades educacionais em todas as } \\
\text { escolas das redes de ensino pública } \\
\text { e privada }\end{array}$ \\
\hline \multirow[b]{2}{*}{$01 / 04 / 2020$} & \multirow[b]{2}{*}{370} & \multirow[b]{2}{*}{4} & no 40.583 & $\begin{array}{l}\text { Suspensão até o dia } 31 \text { de maio das } \\
\text { atividades educacionais em todas as } \\
\text { escolas das redes de ensino pública } \\
\text { e privada }\end{array}$ \\
\hline & & & $\begin{array}{l}\text { Medida provisória } \\
\text { nº } 934\end{array}$ & $\begin{array}{l}\text { Dispensa, em caráter excepcional, } \\
\text { da obrigatoriedade de observância } \\
\text { ao mínimo de dias de efetivo } \\
\text { trabalho escolar, na educação } \\
\text { básica. }\end{array}$ \\
\hline
\end{tabular}

\footnotetext{
${ }^{1}$ Número de casos confirmados retirado do site oficial do Governo do Distrito Federal e recomendado pelo Ministério da Saúde: http://www.saude.df.gov.br/boletinsinformativos-divep-cieves/
} 


\begin{tabular}{|c|c|c|c|c|}
\hline $22 / 05 / 2020$ & 5.948 & 90 & $\mathrm{n}-40.817$ & $\begin{array}{l}\text { Suspensão das atividades } \\
\text { educacionais em todas as escolas } \\
\text { das redes de ensino pública e } \\
\text { privada, sem data prevista de } \\
\text { retorno. }\end{array}$ \\
\hline $02 / 07 / 2020$ & 52.281 & 631 & $\mathrm{n}-40.939$ & $\begin{array}{l}\text { Autorização de funcionamento a } \\
\text { partir do dia } 27 \text { de julho para a rede } \\
\text { de ensino privada e } 05 \text { de agosto } \\
\text { para a rede pública. }\end{array}$ \\
\hline $25 / 07 / 2020$ & 94.187 & 1275 & $\begin{array}{l}\text { Medida cautelar } \\
\text { expedida pelo juiz } \\
\text { Gustavo Carvalho } \\
\text { Chehab, TRT-10 }\end{array}$ & $\begin{array}{l}\text { Suspensão, por dez dias, das aulas } \\
\text { presenciais nas escolas particulares } \\
\text { do Distrito Federal. }\end{array}$ \\
\hline 06/08/2020 & 118.000 & 1651 & $\begin{array}{l}\text { Desembargador do } \\
\text { TRT-10, Pedro } \\
\text { Luís Vicentin } \\
\text { Foltran, acata } \\
\text { pedido do MPT, } \\
\text { por mandado de } \\
\text { segurança cível }\end{array}$ & $\begin{array}{l}\text { Manutenção da suspensão das } \\
\text { atividades presenciais nas escolas } \\
\text { particulares do Distrito Federal, sob } \\
\text { alegação de o retorno representar } \\
\text { "grave risco de dano à saúde dos } \\
\text { trabalhadores das escolas da rede } \\
\text { particular de ensino, expondo-os ao } \\
\text { contágio da Covid-19 e, } \\
\text { consequentemente, à disseminação } \\
\text { da doença". }\end{array}$ \\
\hline $25 / 08 / 2020$ & 153.690 & 2.344 & $\begin{array}{lr}\quad \text { Acordo } & \text { entre } \\
\text { sindicatos } & \text { de } \\
\text { profissionais } & \text { da } \\
\text { educação } & \text { e } \\
\text { Ministério } & \text { Público } \\
\text { do Trabalho } & \end{array}$ & $\begin{array}{l}\text { Retorno das aulas presenciais para } \\
\text { Educação Infantil e Ensino } \\
\text { Fundamental I, em } 21 \text { de setembro, } \\
\text { para instituições da rede privada de } \\
\text { ensino. }\end{array}$ \\
\hline $27 / 09 / 2020$ & 189.513 & 3.097 & - & $\begin{array}{l}\text { Data em que as escolas da rede } \\
\text { privada foram autorizadas a } \\
\text { retomar as atividades presenciais. }\end{array}$ \\
\hline $05 / 10 / 2020$ & 195.967 & 3.346 & - & $\begin{array}{c}\text { Data de retorno } \\
\text { da escola em questão. }\end{array}$ \\
\hline
\end{tabular}

Fonte: Desenvolvido pelas autoras (2021).

Interpreta-se o quadro acima seguindo a estruturação de leitura, esquerda para direita, linha por linha. Comparando-se as colunas, têm-se os marcos cronológicos em relação as decisões judiciais que influenciaram diretamente as instituições de ensino. A segunda e terceira coluna registram o número total de casos confirmados e o número total de óbitos registrados, respectivamente, até o momento da data indicada na primeira coluna, quando novos decretos foram publicados no DODF quarta coluna. Por fim, na última coluna, pontuou-se, brevemente, o impacto deste decreto no contexto escolar.

No primeiro questionário enviado às famílias, no dia 29 de maio, o cenário da pandemia no DF continuava a se agravar. Os números de casos e óbitos estavam em crescimento acentuado, ainda sem indícios de a curva de contágio ter alcançado o chamado platô. ${ }^{2}$ Nesse mesmo período, estava sendo implementada a flexibilização gradual do comércio, com a reabertura escalonada dos estabelecimentos por setor, ainda com resistência e crítica por parte da mídia. Assim, o retorno às atividades presenciais ainda não era vislumbrado em um futuro próximo, pela escola e pelas famílias, a despeito do Decreto no 40.583, que previa a suspensão do funcionamento das escolas apenas até o dia 31 de maio. O questionário teve como objetivo, então, obter

\footnotetext{
${ }^{2}$ Estabilização no número de novos casos confirmados da doença: não há aumento nem redução significativos referentes a esses números. A variação é pequena.
} 
um feedback das famílias sobre a experiência do ensino remoto on-line, para que a escola pudesse identificar os aspectos que precisavam ser melhorados e os que mereciam mais atenção do corpo pedagógico, bem como os aspectos avaliados como satisfatórios pelas famílias.

Os resultados das respostas referentes aos alunos da Educação Infantil (EI), do Maternal I ao Jardim II, e do Ensino Fundamental I (EF), do primeiro ao quinto ano, foram analisados separadamente, tendo em vista as diferentes fases do desenvolvimento de cada faixa etária, bem como as demandas específicas em relação às aulas on-line. Na EI, foram obtidas 115 respostas e, no EF, 185, totalizando 300 avaliações das aulas on-line.

O primeiro item do questionário solicitava que a família avaliasse de 1 a 5 (sendo 1 muito insatisfeito e 5 muito satisfeito), de modo geral, a plataforma adotada. Na EI, $84 \%$ das famílias indicaram muita satisfação ou satisfação, indicação também de 88\% das famílias com filhos no EF. Em seguida, no item em que avaliaram, de modo geral, o formato das aulas online, as respostas de ambos os segmentos também foram semelhantes, tendo a maioria dos respondentes nos dois grupos ( $72 \% \mathrm{e}$ $80 \%$, respectivamente) indicado muita satisfação ou satisfação. Esses dados, apesar de não diretamente relacionados aos objetivos, foram considerados relevantes, pois sugerem que as dificuldades enfrentadas nas aulas remotas não são em função da plataforma utilizada e nem por dificuldades técnicas por parte das famílias.

Outros resultados congruentes entre si nos dois grupos dizem respeito à avaliação da interação da professora com a turma como boa ( $56 \%$ na EI e 50\% no EF), bem como os aspectos avaliados como positivos na modalidade on-line, com destaque para a didática da professora ( 89 votos na EI; 147 votos no EF) e para a comunicação da professora ( 97 votos na EI; 148 votos no EF). Tais dados indicam que, apesar da mudança drástica e sem preparo prévio, o corpo docente conseguiu se adaptar de forma muito repentina e intensa às transformações do ensino/aprendizagem deste período de pandemia (Castaman \& Rodrigues, 2020). As famílias consideraram essa rápida adaptação positiva e necessária para que o ensino remoto funcionasse. Essa exigência, entretanto, custou aos docentes sobrecarga física e mental, aumentando o preexistente desgaste vivenciado por esses profissionais, acarretando um agravo na saúde mental das professoras neste período de pandemia (Pereira, Santos \& Manenti, 2020).

Quando solicitadas a indicar o que poderia ser aperfeiçoado nas aulas on-line, as famílias de alunos tanto da EI quanto do EF votaram em sua maioria no item "Desativar os microfones durante a aula", com 53 e 103 votos, respectivamente, e, em seguida, no item "Esclarecer aos pais o apoio que precisam dar aos filhos", com 52 e 98 votos. O primeiro item, apesar de fazer referência a um aspecto de caráter predominantemente técnico da ferramenta de ensino utilizada, evidencia as dificuldades enfrentadas em um modelo de ensino que foi implementado sem a devida capacitação dos docentes (Dias \& Pinto, 2020). Quanto à percepção dos pais de que poderiam ser mais bem orientados em como apoiar seus filhos nas atividades escolares, esse é um ponto de reflexão importante sobre o ensino remoto. Cifuentes-Faura (2020) destaca que, apesar do comprometimento das famílias com a educação dos filhos, há limitações pessoais, cognitivas, materiais, intelectuais e de disponibilidade de tempo que precisam ser consideradas e que variam entre as famílias. Assim, as instituições de ensino precisam ponderar a expectativa que atribuem aos responsáveis neste momento (Dias \& Pinto, 2020) e buscar estabelecer um diálogo direto, a fim de orientar, esclarecer dúvidas e flexibilizar atividades, adequando, na medida do possível, à realidade de cada família.

Em contrapartida, algumas diferenças significativas foram identificadas entre os dois grupos. Como exemplo, estão as principais dificuldades percebidas pelas famílias, que, para a EI, é a baixa concentração das crianças durante a aula (69 votos) e, para o EF, são as crianças conversando no chat (41 votos). No que diz respeito à interação da criança com a turma, as avaliações também diferiram entre os dois grupos, tendo a maioria das famílias responsáveis por crianças da EI percebido que há pouca interação entre colegas (39\%) ou que não há interação (24\%), ao passo que no EF houve uma divisão de opiniões, a maioria das famílias (36\%) avaliando como boa a interação da criança com a turma, e 32\% considerando haver pouca interação. 
As diferenças identificadas nas faixas etárias eram esperadas, uma vez que crianças mais novas, da Educação Infantil, são mais dependentes de estimulação direta e concreta, tais como ambiente físico, contatos físico e visual acompanhados de comandos verbais (Pasqualini \& Eidt, 2020), e, a partir dos seis anos aproximadamente, já demonstram mais independência em suas relações entre pares e com o ambiente, além de maior capacidade de abstração.

Outro ponto avaliado foi em relação ao aspecto emocional das crianças frente às aulas on-line, na perspectiva das famílias. Nesse momento 34\% das famílias da EI ressaltaram que suas crianças se mostram animadas com as aulas on-line; no EF esse número sobe para 57\%. Em uma breve análise, os alunos com idades mais avançadas se mostravam, no momento da pesquisa, mais animados para assistir às aulas, na percepção de seus pais. Em contrapartida, os alunos da EI, que são mais novos, não pareciam tão entusiasmados com as aulas on-line. Esse aspecto será discutido mais adiante, com outras informações.

\section{On-line x offline: a mudança de perspectiva}

O segundo questionário enviado às famílias foi elaborado após a publicação do Decreto no 40.939 , de 02 de julho de 2020, autorizando os estabelecimentos da rede particular de ensino que optarem pelo retorno às atividades presenciais a fazê-lo a partir de 27 de julho. É pertinente destacar que esse mesmo decreto regulamentou o funcionamento de salões de beleza, barbearias, esmalterias, centros estéticos e academias de esporte a partir de 7 de julho; e bares e restaurantes a partir de 15 de julho. Até 02 de julho, o DF havia registrado 52.281 casos de infecção e 631 óbitos. Nesse contexto, considerando o caráter opcional de retorno às atividades presenciais, a escola em questão avaliou ser importante ouvir os interesses dos responsáveis pelos alunos sobre a possibilidade de retorno, para uma tomada de decisão prudente e de acordo com as necessidades das famílias.

Nesse primeiro levantamento sobre a perspectiva do retorno do modo presencial, foram obtidas 853 respostas, o que corresponde a 1.183 crianças, pois algumas famílias possuem mais de um filho na escola. Em uma análise macro, identificou-se que 79\% das famílias não acreditavam que 27 de julho fosse a opção adequada para o retorno. Dos respondentes responsáveis por crianças da EI, 77,5\% não tinham interesse pelo retorno, escolha compartilhada por 80\% dos pais de alunos do EF, como demonstra-se no Gráfico 1, abaixo.

Gráfico 1. Distribuição das respostas das famílias referente ao primeiro levantamento sobre a perspectiva de retorno presencial.

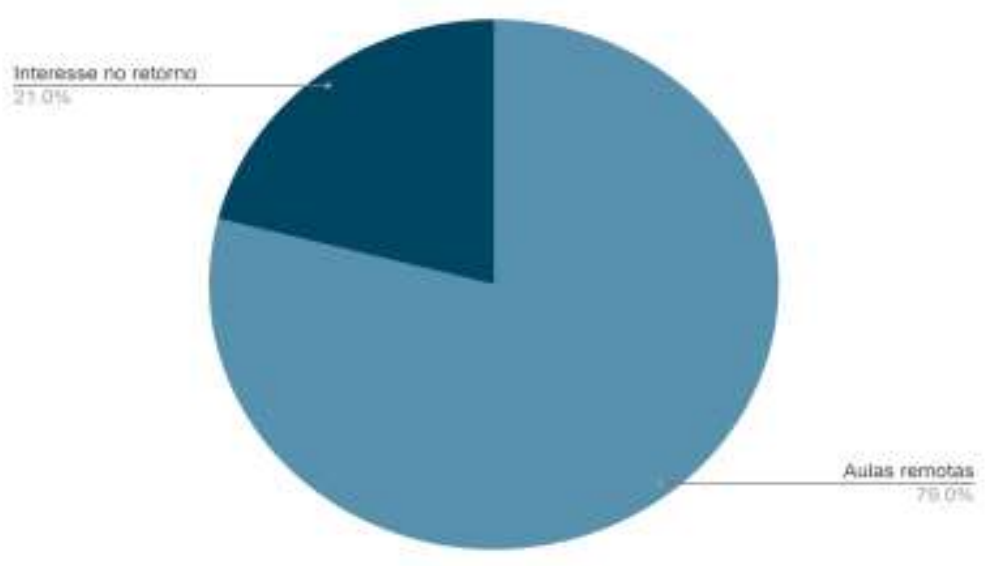

Fonte: Autores (2021).

A análise do Gráfico 1 demonstra que quase 21\% das famílias tinha interesse no retorno presencial e que apenas $79 \%$ continuariam nas aulas remotas. Na seção de justificativa, as famílias poderiam assinalar quantos itens julgassem necessários. Em ambos os segmentos focalizados, os itens que receberam mais votos foram "Não opto pelo retorno às atividades presenciais, 
pois não estou segura com os riscos reais de transmissão do coronavírus." e "Opto pela continuidade das aulas on-line, pois ainda não estou segura de mandar meu filho para as atividades presenciais.", que, semanticamente, se assemelham.

Apesar da retomada de diversas outras atividades de comércio, alimentação, esporte e lazer, poucas famílias justificaram a opção pelo retorno presencial pelo fato de não ter com quem deixar seus filhos durante o dia, uma vez que não estariam mais cumprindo a modalidade de teletrabalho, fator que preocupava a equipe da escola. Dos 415 respondentes da EI, apenas 15 indicaram essa justificativa, e, dos 767 respondentes do EF, apenas 25 .

No final de setembro, quando as famílias já estavam cientes de que ocorreria o retorno presencial, foi enviado o terceiro e último questionário, que visava realizar um segundo levantamento em relação à perspectiva das famílias sobre o retorno presencial. Foram obtidas respostas referentes a 625 alunos, 345 dos quais interessados pelo retorno presencial. Analisando-se o total de alunos em comparação aos que informaram interesse no retorno presencial, apenas $24,6 \%$ dos estudantes eram esperados na escola, conforme Gráfico 2, inferior. Cabe, a partir disso, a reflexão sobre alguns dados e, em especial, levantar algumas outras questões do cenário escolar.

Gráfico 2. Distribuição das respostas das famílias referente ao segundo levantamento sobre a perspectiva de retorno presencial.

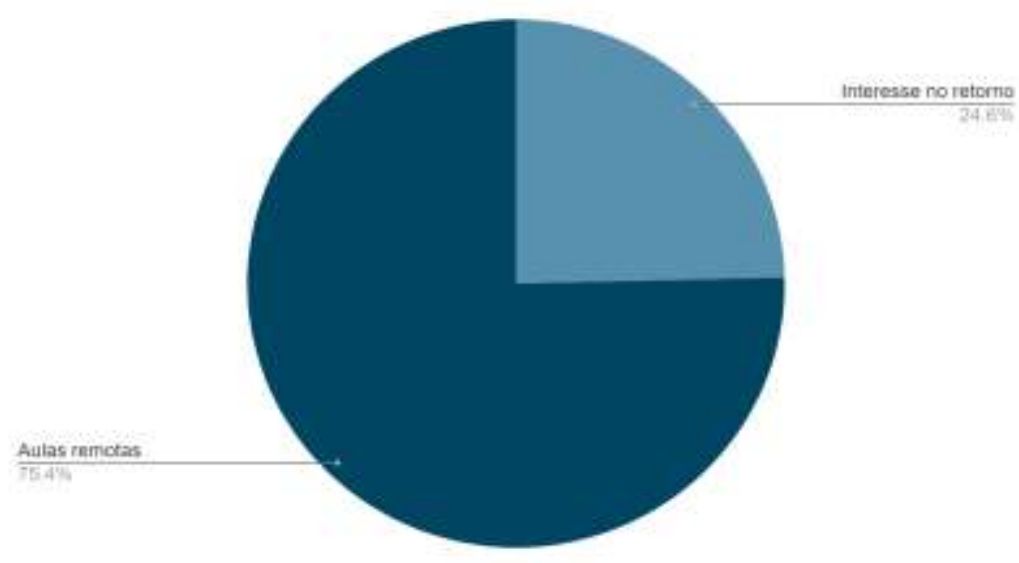

Fonte: Autores (2021).

A análise do Gráfico 2 demonstra que quase 25\% das famílias tinham interesse no retorno presencial e que apenas 75\% continuariam nas aulas remotas. Em 25 de agosto, quando foi estabelecido o acordo entre sindicatos e MPT, o DF registrava 153.690 casos de infecção e 2.344 de óbitos; em 05 de outubro, dia da retomada das atividades presenciais pela escola em questão, os casos de infecção haviam subido para 195.967, e os de óbito para 3.346. A rede de ensino analisada comprometeuse a seguir os protocolos de segurança decretados, mas também responsabilizou as famílias que concordaram com o retorno presencial, no sentido de que seguissem as medidas impostas. Cabe assim ressaltar que, após as primeiras semanas de retorno, outras famílias procuraram a escola solicitando o retorno presencial de suas crianças. Não houve outros encaminhamentos de questionários para escalonar o retorno presencial. A autorização passou a ser por meio de e-mail institucional. Ao final do ano letivo, em 22 de dezembro de 2020, retornaram presencialmente à instituição de ensino analisada 267 alunos da Educação Infantil e 489 alunos do Ensino Fundamental I, totalizando 726 alunos, conforme ilustra o Gráfico 3 abaixo. 
Gráfico 3. Retorno presencial x Aulas remotas.

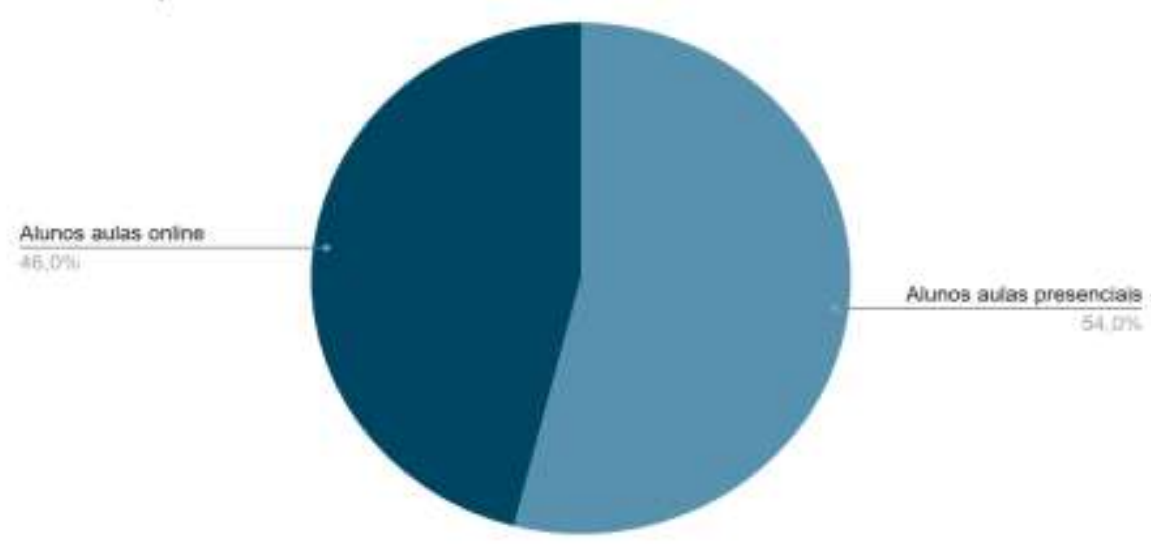

Fonte: Autores (2021).

Como indica o Gráfico 3 acima, mais da metade do total de alunos da escola retomaram as atividades presenciais até o final do ano letivo. Devido à demanda crescente do retorno, foi necessário realizar rodízio em algumas turmas cujo número de alunos ultrapassou o limite das exigências acordadas no decreto e pelo sindicato, ${ }^{3}$ ou seja, foi preciso separar os alunos em dois grupos, alternando os dias de presença na escola com as aulas on-line em casa. No Ensino Fundamental I, sete turmas foram submetidas a tal modalidade; na Educação Infantil, apenas uma. Cabe destacar que, embora desde o princípio das consultas aos familiares essa decisão constasse nos protocolos de retorno presencial, houve grande descontentamento dos responsáveis quando foi preciso colocar em prática o sistema híbrido.

O que os pais alegavam, como ponto de maior insatisfação era o fato de não ter mais condições de partilhar a administração das atividades on-line do filho com seu próprio trabalho, além de questões financeiras, pois estavam pagando pela escola. Esses mesmos pontos apareceram nos meses de outubro e novembro como justificativas dos pais ao solicitar por e-mail o retorno presencial de seus filhos.

Com base em tais levantamentos, dois pontos de análise e reflexão são imprescindíveis e podem ser associados; o primeiro deles é a mudança de perspectiva: nas respostas ao primeiro questionário, $79 \%$ das famílias não concordavam com o retorno presencial, porém, no final do ano, 54\% dos alunos retornaram à escola, ainda que as aulas remotas continuassem sendo oferecidas no mesmo formato de antes. Concomitantemente com o aumento crescente das crianças no retorno presencial, ampliava-se o número de casos referentes à Covid-19 no DF: no mês de julho, Brasília contava com 52.281 casos, em outubro com 194.042 casos e ao final do ano com 245.872 .

Nesse ponto, Galhardi et al. (2020) argumentam que a descrença de muitos brasileiros em relação à periculosidade da doença se deve a alguns fatores, entre eles as declarações divergentes das autoridades governamentais, o que faz com que a população se sinta confusa e desinformada, pois ciência, política, economia e saúde não corroboram em uma mesma linha de pensamento. Simultaneamente, a abertura dos espaços públicos, como comércio e clubes, fez com que muitos pensassem que a pandemia já estivesse mais amena.

Em paralelo a tudo isso, eram perceptíveis, em diversas famílias, o desgaste emocional, a incapacidade de conciliar diferentes demandas na rotina, a sobrecarga no trabalho, a questão financeira e a inabilidade para lidar com os filhos após tanto tempo em casa. Isso nos leva ao segundo ponto de reflexão e análise. Silva et al. (2021), com referência a outra realidade escolar,

\footnotetext{
${ }^{3}$ Exigências para o retorno presencial nas escolas, segundo o decreto no 40.939 .
} 
apontam também esses pontos como problemáticas, em que a atuação da psicologia escolar se torna ainda mais essencial não somente com os alunos, mas com toda a comunidade que a escola compõe.

Percebe-se que o isolamento social surge como um aspecto agravante de saúde mental a todo o público que se encontra no contexto escolar. E o papel da psicologia nesse âmbito é primordial, pois atua diretamente ao gerenciamento de crises e contribui com a adaptação das novas medidas de prevenção, auxiliando pais, alunos, professores e toda a gestão inserida, com a finalidade de amenizar o impacto do atual cenário (Silva et al., 2021, p. 513).

Ainda no primeiro questionário enviado às famílias, sobre as aulas on-line, uma das questões dizia respeito ao entusiasmo das crianças, pela perspectiva dos pais. Nas respostas já aparecia um baixo percentual (34\% na EI) em relação ao entusiasmo das crianças menores com as aulas remotas. Apesar do percentual de 57\% para o EF no mesmo item - o que já não era uma quantidade tão considerável dado o número de respondentes -, acredita-se que houve redução, em uma visão qualitativa. Afinal, as famílias, ao longo dos atendimentos e e-mails, traziam esse ponto como preocupação. Fonseca (2016), comenta o impacto das emoções na aprendizagem, em que fatores como o aspecto social, a motivação, o interesse e a segurança podem influenciar o estado emocional e, por consequência, as funções cognitivas. É por meio da emoção que o processamento das informações ocorre, afetando a atenção e a memória. Assim, caso um aluno não se sinta emocionalmente preparado, isso afetará diretamente sua aprendizagem, principalmente se não tiver apoio de um mediador seguro e confiável.

Azevedo et al. (2021), observando que as demandas das famílias estavam aumentando em uma perspectiva similar de esgotamento emocional em meio à pandemia, propuseram um projeto de educação emocional, com o intuito de acolher e gerar pontos de reflexão na comunidade escolar sobre a importância de trabalhar as emoções das crianças e, em paralelo, também a dos adultos que as cercam. O autoconhecimento se torna fator essencial para que situações inesperadas possam ser vivenciadas de forma mais amena, apesar de todo abalo emocional envolvido.

A psicologia escolar, em sua atuação, possui um posicionamento crítico e reflexivo, pensando a escola como um fenômeno ativo e construtivo, associado a todos os que a compõem. Por isso a importância de pensar em um cenário antes e durante o retorno presencial de todos, como auxílio às famílias, aos alunos e aos professores, atuando nas habilidades emocionais e educacionais, para que o prejuízo de 2020 não se prolongue nos anos seguintes (Pedroza \& Maia, 2021). Corroborando essa perspectiva, a preparação emocional para o retorno presencial é algo que precisa ser colocado em pauta, assim como a disparidade entre a educação na escola pública e na escola privada, que se acentuou neste último ano, com a pandemia.

\section{Conclusão}

A partir das discussões propostas, é possível afirmar que o retorno às aulas presenciais na rede privada de ensino no DF não se deu em função da melhora do contexto da pandemia, que continuou a se agravar, mas principalmente devido à sobrecarga dos cuidadores das crianças, que acumularam diversas funções nunca antes desempenhadas com tamanha intensidade. Além disso, a percepção dos pais e das mães quanto à necessidade dos filhos de socializar e frequentar outros ambientes, além do doméstico, também impulsionou o retorno gradativo às atividades presenciais. Outra questão evidenciada foi a habilidade dos docentes com relação à rápida adaptação ao ambiente virtual, mantendo a didática e a criatividade nas aulas, apesar de todo o desgaste psicológico e físico ocasionados pela pandemia. A situação emocional das crianças, bem como a dos adultos responsáveis e dos professores, mostrou-se, mais do que nunca, essencial ao contexto acadêmico e à realização das atividades propostas, reafirmando o papel da psicologia no ambiente escolar, focalizando não apenas os alunos, mas também as famílias e os profissionais da instituição.

E quanto a 2021? Caso a situação pandêmica não se agrave, já está definido o padrão nas escolas particulares. Grande parte delas se estruturou para receber os alunos presencialmente ainda no final de 2020 e continuará com práticas similares em 2021. Por outro lado, até então não houve posicionamento de como ocorrerá o retorno presencial nas escolas públicas. Essa é 
uma questão que merece atenção e políticas públicas específicas, pois a diminuição da renda de muitas famílias somada à evasão escolar impulsionada pelo ensino remoto, vulnerabiliza ainda mais crianças e adolescentes de baixa renda, que ficam mais expostos à fome, ao trabalho infantil e a violências (Castro, 2020). Apesar de o presente relato se basear na experiência em uma instituição particular, profissionais da educação devem estar sempre atentos à educação brasileira como um todo, principalmente à parcela mais vulnerável da população.

Ao mesmo tempo em que as escolas da rede privada precisaram se reestruturar para o retorno presencial, com disputas judiciais e alguns interesses particulares, cabe uma crítica reflexiva à situação da rede pública de ensino. A forma como foram afetados os diferentes grupos não é uma questão que se iniciou com a pandemia, pelo contrário, a crise da Covid-19 apenas intensificou essa realidade. A começar pelo acesso ao ensino remoto, havendo nas escolas públicas carência de recursos financeiros e técnicos para adaptação à nova realidade. $\mathrm{O}$ apoio da família nas aulas on-line também constitui ponto de discussão, pois, muitos pais de alunos da rede pública não ficaram em home office, se expondo mais ao risco de contaminação e, por conseguinte, acompanhando consideravelmente menos o filho. Além disso, segundo dados do Instituto Brasileiro de Geografia e Estatística (IBGE), cerca de 30\% dos domicílios brasileiros não dispõem de internet, e os que dispõem possuem o celular como principal acesso à tecnologia, sendo que em $57 \%$ dos domicílios não há computador. Tais dados por si só colocam em estado de atenção as condições para atividades remotas. A desigualdade social recorre ao desespero, configurando uma sociedade ainda mais segregada, em que os privilégios de quem pode pagar por uma escola particular não beneficiarão quem precisa depender de ações governamentais (Senhoras, 2020; Moraes et al., 2021). Cabe então o ponto de crítica e reflexão: O retorno presencial é uma realidade da necessidade ou da desigualdade? Necessidade das escolas particulares frente à pandemia ou aumento da desigualdade, quando comparadas a rede privada e a rede pública?

Em 17 de janeiro, quando se escreviam os detalhes finais deste artigo, a vacina foi autorizada no Brasil pela Agência Nacional de Vigilância Sanitária (Anvisa). Novas perspectivas são almejadas, porém, os cuidados ainda precisam ser mantidos até que grande parcela da população esteja imunizada, pois já estão sendo cogitadas novas variantes do coronavírus. Por isso, é urgente e importante refletir e questionar decisões governamentais e o retorno presencial em diferentes perspectivas e considerando o ponto de vista de todos os envolvidos, o que poderia, inclusive, suscitar em novos estudos comparativos em futuros trabalhos. Na data de submissão deste artigo, o número de mortes por Covid-19 chegara a 4.838, no Distrito Federal, o de infectados a 296.694, e o de novos casos a 1.079. Um novo decreto, $\mathrm{n}^{\mathrm{o}} 41.842$, publicado em 26 de fevereiro de 2021 determinou novamente o fechamento das escolas particulares e o adiamento do retorno presencial para a rede pública de ensino, que estava com previsão para dia primeiro de março. Neste lockdown, as escolas da rede privada já estão familiarizadas com o ensino remoto, ao passo que profissionais e alunos da rede pública continuam enfrentando os desafios bem similares ao vivenciados em 2020.

Recomenda-se que os dados apresentados e a pesquisa realizada possam contribuir para futuros trabalhos relacionados a novas decisões judiciais que impactam no contexto escolar. Além disso, considerando-se a chance de uma nova cepa da família dos coronavírus no Brasil e o prolongamento de medidas de proteção, que recomendam sistemas híbridos e sistemas remotos de ensino, é importante ter uma visão coerente e responsável relacionada a essa nova realidade. Dessa forma, espera-se que o presente estudo possa influenciar nas políticas públicas educacionais, a fim de diminuir a discrepância entre a estruturação de ensino na rede pública e privada, em um momento que é tão delicado, sendo essencial que a empatia seja posta a prova.

\section{Referências}

Azevedo, R. L., Mieto, G. S. de M., Buchamann, B. M., Nolasco, A. C. G., \& Lopes, L (2021). O ciclo das emoções: relato de experiência da psicologia escolar, no contexto de distanciamento social, com crianças e suas famílias. In: Negreiros, F. \& Ferreira, B. de O. (Orgs.). Onde está a psicologia escolar no meio da pandemia? Pimenta Cultural, p. 371-397.

Castaman, A. S., \& Rodrigues, R. A. (2020). Educação a distância na crise Covid-19: um relato de experiência. Research, Society and Development, 9(6), 1-26. 
Castro, J. A. (2020). Proteção social em tempos de Covid-19. Saúde em debate, 44(4e), 88-99.

Cifuentes-Faura, J. (2020). Consecuencias en los niños del cierre de escuelas por Covid-19: el papel del gobierno, profesores y padres. Revista Internacional de Educación para la Justicia Social, 9(3e), 1-12.

Dias, E., \& Pinto, F. C. F. (2020). A educação e a Covid-19. Ensaio: avaliação e políticas públicas em educação, 28(108), 545-554. <https://doi.org/10.1590/s0104-40362019002801080001>.

Distrito Federal. Decreto $n^{\circ}$ 40.509, de 11 de março de 2020. Dispõe sobre as medidas para enfrentamento da emergência de saúde pública de importância internacional decorrente do novo coronavírus, e dá outras providências. Diário Oficial do Distrito Federal. Brasília: Poder Executivo, 11 mar. 2020 , edição extra, Seção 1, p. 3. <http://www. buriti.df.gov.br/ftp/diariooficial/2020/03_Mar\%C3\%A7o/DODF\%20025\%20 11-032020\%20EDICAO\%20EXTRA/DODF\%20025\%2011-03-2020\%20 EDICAO\%20EXTRA.pdf>.

Distrito Federal. Decreto n ${ }^{\circ}$ 41.842, de 26 de fevereiro de 2021. Dispõe sobre as medidas para enfrentamento da emergência de saúde pública de importância internacional decorrente da COVID-19 (Sars- Cov - 2), e dá outras providências. Diário Oficial do Distrito Federal. Brasília: Poder Executivo, 26 fev. 2021, edição extra, Seção 1, $1<\mathrm{https} / / /$ www.dodf.df.gov.br/index/visualizar-arquivo/?pasta=2021|02_Fevereiro|DODF\%20014\%2026-022021\%20EDICAO\%20EXTRA\%20B|\&arquivo=DODF\%20014\%2026-02-2021\%20EDICAO\%20EXTRA\%20B.pdf>.

Fonsceca, V. (2016). Importância das emoções na aprendizagem: uma abordagem neuropsicopedagógica. Revista Psicopedagogia, 33(102), 365-384. http://pepsic.bvsalud.org/scielo.php?script=sci_arttext\&pid=S0103-84862016000300014\&lng=pt\&tlng=pt.

Fundação Oswaldo Cruz. Documento sobre crianças na pandemia Covid-19. <https://www.arca.fiocruz.br/bitstream/icict/41182/2/Cart ilhaCrianças_Pandemia.pdf>.

Fundo das Nações Unidas para a Infância. (2005). Crianças de até 6 anos. O direito à sobrevivência e ao desenvolvimento. <https://crianca.mppr.mp.br/arquivos/File/publi/unicef_sowc/sit_inf_brasil_2006_completo.pdf>.

Galhardi, C. P., Freire, N. P., Minayo, M. C. de S., \& Fagundes, M. C. M. (2020). Fato ou fake? Uma análise da desinformação frente à pandemia da Covid-19 no Brasil. Ciência \& Saúde Coletiva, 25 (sup. 2), p. 4201-4210. <https://doi.org/10.1590/1413-812320202510.2.28922020>.

Linhares, M. B. M., \& Enumo, S. R. F. (2020). Reflexões baseadas na Psicologia sobre efeitos da pandemia COVID-19 no desenvolvimento infantil. Estudos de Psicologia (Campinas), 37, e200089. https://doi.org/10.1590/1982-0275202037e200089

Lüdke, M., \& André, M. E. D. A. (1986). Pesquisa em educação: abordagens qualitativas: EPU.

Maia, J. M. D., \& Williams, L. C. A. (2005). Fatores de risco e fatores de proteção ao desenvolvimento infantil: uma revisão da área. Temas em Psicologia, 13(2), p. 91-103.

Ministério da Educação. Medida Provisória n 934, de 1 de abril de 2020. Dispõe sobre normas excepcionais sobre o ano letivo da educação básica e da educação superior decorrentes das medidas para enfrentamento da situação de emergência de saúde pública. Brasília: Ministério da Educação. <http://www.in.gov.br/en/web/dou/-/medida-provisoria-n-934-de-1-de-abril-de-2020-250710591>.

Ministério da Mulher, da Família e dos Direito Humanos. Lei no 8.069 de 13 de julho de 1990. Dispõe sobre o Estatuto da Criança e do Adolescente e dá outras providências. Brasília: Ministério da Mulher, da Família e dos Direito Humanos. <https://www.gov.br/mdh/pt-br/centrais-de-conteudo/crianca-eadolescente/estatuto-da-crianca-e-do-adolescente-versao-2019.pdf>.

Moraes, C. M., Barros, M. O., Araújo, M. G. N., Silva, R. B. A., \& Negreiros, F. (2021). Aprendizagem e ensino remoto emergencial no contexto da pandemia da covid-19: o que famílias do Piauí têm revelado. In: Negreiros, F. \& Ferreira, B. de O. (Orgs.). Onde está a psicologia escolar no meio da pandemia?: Pimenta Cultural, 287-327.

Oliveira, C. B. E., \& Marinho-Araújo, C. M. (2010). A relação família/escola: intersecções e desafios. Estudos de Psicologia, 27(1), p. 99-108. <https://doi.org/10.1590/S0103-166X2010000100012>.

Oliveira, J. B. A., Gomes, M., \& Barcellos, T. (2020). A Covid-19 e a volta às aulas: ouvindo as evidências. Ensaio: avaliação e políticas públicas em educação, Rio de Janeiro, 28(108), 555-578.

Pasqualini, J. C., \& Eidt, N. M. (2020). Periodização do desenvolvimento infantil e ações educativas. In: Pasqualini, J. C., \& Tsuhako. Y. N. (Orgs.). Proposta pedagógica para a educação infantil do Sistema Municipal de Ensino de Bauru: Secretaria Municipal de Educação, $101-148$.

Pedroza, R. L. S., \& Maia, C. M. F. (2021). Atuação de psicólogas escolares em contexto de pandemia: análise de práticas profissionais. In: Negreiros, F., \& Ferreira, B. de O. (Orgs.). Onde está a psicologia escolar no meio da pandemia? Pimenta Cultural, p. 91-117.

Pereira, A. S., Shitsuka, D. M., Pereira, F. J., \& Shitsuka, R. (2018). Metodologia de pesquisa científica. UFSM. https://repositorio.ufsm.br/bitstream /handle/1/15824/Lic_Computacao_Metodologia-Pesquisa-Cientifica.pdf?sequence=1.

Pereira, H. P., Santos, F. B., \& Manenti, M. A. (2020). Saúde mental de docentes em tempos de pandemia: os impactos das atividades remotas. Boletim de Conjuntura (Boca), Boa Vista, ano II, 3(9).

Schmidt, B., Crepaldi, M. A., Bolze, S. D. A., Neiva-Silva, L., \& Demenech, L. M. (2020). Saúde mental e intervenções psicológicas diante da pandemia do novo coronavírus (COVID-19). Estudos de Psicologia, Campinas, 37, p. 1-13.

Senhoras, E. M. (2020). Coronavírus e educação: análise dos impactos assimétricos. Boletim de Conjuntura (Boca), 2(5), $128-136$.

Silva, D. de C., Sousa, C. P., Lemos, A. C. G., Ribeiro, M. de M., \& Rodrigues, L. C. S. (2021). Desafios na educação em tempos de pandemia: contribuições da psicologia escolar. In: Negreiros, F. \& Ferreira, B. de O. (Orgs.). Onde está a psicologia escolar no meio da pandemia? Pimenta Cultural, p. $490-517$. 